Contemporary China furnishes a good example. Compared with the rapid development in big cities and in the commercial and industrial sectors of the coastal areas, a combination of adverse factors, including a low income growth rate, heavy tax burdens and surplus labour have hindered economic development, intensified poverty, and threatened social stability in rural China, which is inhabited by a staggering 900 million population (Liu, 1995). Along with gender inequalities and the one-child-per-couple policy adopted since 1980, these social forces have underprivileged rural women. Although the one child policy is responsible for China's remarkable success in population control and is relatively well accepted by urban couples, it drastically clashes with the entrenched value of duo zi duo sun ("having more sons and grandsons"), which is integral to agrarian subsistence and rural women's social status. Ethnographic studies revealed that women who gave birth to baby girls were fearful about not carrying on the lineage, the loss of extra labour power, and not having someone to provide for them in old age. They experienced a loss of face, alienation, and often physical abuse (Pearson, 1995). In such an oppressive context, depressive and anxiety disorders may also be understandable reactions to the brutality of everyday deprivation that will respond less to psychotropic agents than socially meaningful forms of empowerment.

Desjarlais, R., Eisenberg, L., GoOD, B., et al (1995) World Mental Health: Problems and Priorities in Low-Income Countries. Oxford: Oxford University Press.

LIU, Y. H. (1995) The rural economy of China. China Review 22, $1-22$.

Mumford, D. B., NAzIR, M., Jilani, F. U. M., et al (1996) Stress and psychiatric disorder in the Hindu Kush. A community survey of mountain villages in Chitral, Pakistan. British Journal of Psychiatry, 168, 299-307.

Pearson, V. (1995) Goods on which one loses: women and mental health in China. Social Science \& Medicine, 41, 1150-1173.

Prince of Wales Hospital

S. LEE

Shatin, Hong Kong

\section{Lithium revisited}

SIR: I am pleased that my editorial (Moncrieff, 1995) has provoked some discussion but I do not believe that I made any erroneous statements about Coppen et al's (1971) trial (Coppen, 1996). The paper presented results for 65 patients but only 37 of these had bipolar disorder and the number of subjects who did not complete the first 16 weeks of treatment was not documented in the original report. I criticised the study for failing to do an "intention to treat" analysis as the comparability of the residual groups cannot be assumed. The presentation of results was also unsatisfactory with no information on the number or polarity of episodes and global assessment scores combined in various ways that were not specified $a$ priori. In addition diagnosis of illness episodes and administration of additional treatments may have been influenced by unblinding effects, emphasised again by Double (1996). Meta-analysis with the trials I reviewed would only reflect and amplify previous problems.

The follow up study cited (Fieve et al, 1976), which concerned a mixed group of bipolar and unipolar patients taking lithium did not demonstrate unequivocal success. Fourteen per cent of patients were admitted during the course of one year, $20 \%$ were prescribed neuroleptics and $37 \%$ antidepressants and it is likely that rates of morbidity were higher in the bipolar group, which was not examined separately (Coppen \& Abou-Saleh, 1988).

COPPEN, A. (1996) Lithium revisited (Letter). British Journal of Psychiatry, 168, 382.

- , Noguera, R. \& BaIley, J. (1971) Prophylactic lithium in affective disorders. Lancet, ii, 275-279.

- \& ABOU-SAleH, M. T. (1988) Lithium therapy: clinical trials to practical management. Acta Psychiatrica Scandinavia, 78, 756762.

DouBle, D. B. (1996) Lithium revisited (Letter). British Journal of Psychiatry, 168, 381-382.

Fieve, R. R., Kumbaraci, T. \& Dunner, D. L. (1976) Lithium prophylaxis of depression in bipolar I, bipolar II and unipolar patients. American Journal of Psychiatry, 133, 925-929.

MONCRIEFF, J. (1995) Lithium revisited. A re-examination of the placebo-controlled trials of lithium prophylaxis in manic-depressive disorder. British Journal of Psychiatry. 167, 569-572.

Institute of Psychiatry

J. MONCRIEFF

\section{London SE5 8AZ}

\section{Minor physical and factual anomalies}

SIR: In their article on minor physical anomalies (MPAs) and schizophrenia, Murphy \& Owen (1996) state

"The majority of proponents of the neurodevelopmental model have focused on an environmental rather than a genetic explanation for the excess of MPAs seen in schizophrenia (Mednick et al, 1988; Murray et al, 1992)."

In fact, my views are not those Murphy \& Owen attribute to me and the paper they quote contains no statement regarding the causes of MPAs. Elsewhere, in an article which was entitled "The genetics of schizophrenia is the genetics of neurodevelopment", we (Jones \& Murray, 1991) wrote: 